\title{
Preparation of ZnO nanoribbon-MWCNT composite film and its application as antimicrobial bandage, antibacterial filter and thermal IR camouflage material
}

\author{
PRASAD UPASANI ${ }^{1}$, T V SREEKUMAR ${ }^{1}, V_{\text {G GAIKAR }}{ }^{2}$ and NEETU JHA ${ }^{2,3, *}$ \\ ${ }^{1}$ Reliance Technology Group, Reliance Industries Limited, Patalganga, Maharashtra 410220, India \\ ${ }^{2}$ Department of Chemical Engineering, Institute of Chemical Technology, Matunga, Mumbai 400019, India \\ ${ }^{3}$ Department of Physics, Institute of Chemical Technology, Matunga, Mumbai 400019, India \\ *Author for correspondence (jha.neetu@gmail.com; nr.jha@ictmumbai.edu.in)
}

MS received 21 April 2016; accepted 6 September 2016; published online 28 July 2017

\begin{abstract}
A zinc oxide nanoribbon (ZnO NR)-multiwall carbon nanotube (MWCNT) composite film was prepared by filtration technique. The film was characterized by X-ray diffraction spectroscopy, scanning electron microscopy (SEM), Raman spectroscopy, infrared (IR) spectroscopy and reflectance spectroscopy. The SEM images showed ZnO NRs trapped in the porous MWCNT network. This composite film displayed a strong antimicrobial property and porous structure, which has potential application as an antimicrobial bandage material. The composite film successfully removed the Escherichia coli bacteria from water and destroyed the bacteria retained on its surface due to the antibacterial action of ZnO NRs. The absorption of thermal IR radiation by the composite film was studied by thermography, which can be useful in IR camouflage applications.
\end{abstract}

Keywords. Zinc oxide nanoparticles; carbon nanotubes; nanocomposites; antibacterial filters.

\section{Introduction}

Carbon nanotubes (CNTs) exhibit film formation property due to their high aspect ratio and strong Van der Waals forces. These films are known as Buckypapers [1]. Buckypapers are thin, porous, flexible and free-standing films that possess many potential applications like filtration membranes, fire retardant coating, scaffolds for tissue growth, etc. Simmons et al [2] studied the preparation of povidone-iodine single wall carbon nanotube (SWCNT) composite films by the filtration method and its potential application as an antiseptic bandage. The film provided slow release of iodine, which imparted the antibacterial property to the film. It has also been shown that buckypaper incorporated on the surface of epoxycarbon fibre composites imparted fire shielding property to the composite, where the buckypaper acted as an effective flame retardant shield that reduced the release of combustible gases from the polymer underneath and separated these combustible gases from the oxygen to prevent the combustion process, thus reducing the peak heat release rate by more than $60 \%$ and smoke generation by $50 \%$ during combustion [3]. Liu and Saravanan [4] prepared zinc oxide ( $\mathrm{ZnO})$-multiwall carbon nanotube (MWCNT) composite film by the filtration technique, where $\mathrm{ZnO}$ nanoparticles were homogeneously dispersed on the MWCNT film. They proposed that, under illumination, the $\mathrm{ZnO}$ nanoparticles present in the MWCNT network enlarged the photon absorption region, thereby increasing the efficiency of the photocurrent generation, and that the MWCNTs present in the ZnO-MWCNT composite film reduced the possibility of electron-hole recombination process, resulting in efficient photocurrent generation. The high electron transfer rate from $\mathrm{ZnO}$ nanoparticles was attributed to the intimate contact between the $\mathrm{ZnO}$ nanoparticles and the MWCNTs, which enabled rapid dissipation of charge carriers generated in the $\mathrm{ZnO}$ nanoparticles. Such flexible $\mathrm{ZnO}-\mathrm{MWCNT}$ hybrid structures may be useful in applications like multifunctional flexible nanodevices and dye-sensitized solar cells. Diez-Pascual and Gascón [5] prepared a buckypaper-reinforced acrylonitrile butadiene styrene composite film by hot compression and vacuum infiltration method and showed that the composite may be useful in applications like electromagnetic induction shielding and packaging of integrated circuits. Buckypapers have been found to support tissue growth. Leng and Fishman [6] studied the culture of retinal pigment epithelium (RPE) cells on buckypaper surface to demonstrate its application as a cell transplantation substrate. When these buckypapers with cultured RPE cells were implanted underneath rabbit retinas, the RPE cells demonstrated normal morphology and growth patterns on the buckypaper surface, proving the ability of the buckypaper to support tissue growth. Brady-Esétvez et al [7] reported deposition of a layer of SWCNTs on poly(vinylidene fluoride) (PVDF)-based membrane and its application in the removal of Escherichia coli (E. coli) bacteria and MS2 bacteriophage virus by size exclusion mechanism due to the small pore size of the membrane. Rahaman et al [8] reported 
application of CNT sheets with controlled nanoscale porosity in water purification. They evaluated the performance of the filter for virus removal and its inactivation in the presence of natural organic matter and found that application of 2-3 V DC voltage resulted in the complete removal and significant inactivation of MS2 viral particles from the water sample. The enhanced virus removal was proposed to be due to the attractive electrostatic interactions between the viral particles and the anodic MWCNTs. In another study, Sweetman et al [9] prepared MWCNT/SWCNT-ciprofloxacine buckypapers by filtration technique and demonstrated the ability of ciprofloxacin molecules to assist in the dispersion of CNTs in water. The ciprofloxacin molecules were found to be retained in the buckypapers, imparting strong bactericidal property to the composite films. The composite films could efficiently remove the E. coli bacteria from the aqueous suspension, and the bacteria retained on the film surface were destroyed by ciprofloxacine molecules.

The CNTs are known to possess antibacterial property as well. It has been demonstrated previously that SWCNTs are more toxic to bacteria compared to MWCNTs [10], as thin and rigid SWCNTs show more effective piercing of bacterial cell wall. Diameter, length of MWCNTs and functional groups present on the surface are known to affect the antibacterial property of MWCNTs. Long MWCNTs can wrap around the bacteria, which increases the area of contact with the bacterial cell wall, leading to bacterial cell death [11].

Many nanostructures of $\mathrm{ZnO}$ have been reported, including nanoflowers, nanowires, nanoribbons (NRs) and nanoparticles [12]. It has strong antibacterial and antifungal activities [13] and is used in skin care products like antiseptic lotions, baby powders, etc. It has been shown to increase the antibacterial activity of the antibiotic ciprofloxacin [14]. Banoee et al [14] studied the effect of $\mathrm{ZnO}$ nanoparticles on the antibacterial activity of ciprofloxacin using disk diffusion method against Staphylococcus aureus (S. aureus) and E. coli and found a significant enhancement in the antibacterial activity of ciprofloxacin in the presence of $\mathrm{ZnO}$ nanoparticles. Previous studies suggest that treatment of bacteria with $\mathrm{ZnO}$ nanoparticles causes changes in the cell membrane morphology, increasing its permeability and affecting the transport through the plasma membrane. This leaves the bacterial cells incapable of regulating transport through the plasma membrane properly, resulting in cell death $[15$, 16]. Due to their small size, $\mathrm{ZnO}$ nanoparticles can penetrate inside the bacteria and cause damage by interacting with phosphorus and sulphur-containing compounds such as deoxyribonucleic acid (DNA) [16]. The antibacterial activity of $\mathrm{ZnO}$ nanoparticles is also proposed to be due to the generation of reactive oxygen species like hydroxyl radical $\left({ }^{\bullet} \mathrm{OH}\right)$, superoxide radical $\left({ }^{\bullet} \mathrm{O}_{2}^{-}\right)$and hydrogen peroxide $\left(\mathrm{H}_{2} \mathrm{O}_{2}\right)$ on the $\mathrm{ZnO}$ particle surface, which exert strong oxidative stress on the bacterial cell wall, leading to bacterial cell death. Abrasive surface defects like edges and corners present on the $\mathrm{ZnO}$ nanoparticles are known to cause membrane injury, leading to bacterial cell death [12]. Similar to
SWCNTs, due to their small diameter, $\mathrm{ZnO}$ nanorods and nanowires can easily penetrate cell walls of the bacteria, causing bacterial cell wall rupture; however, nanoflowershaped $\mathrm{ZnO}$ has shown higher biocidal activity against $S$. aureus and E. coli than the spherical and rod-shaped $\mathrm{ZnO}$ nanoparticles. Another mechanism of antibacterial action of $\mathrm{ZnO}$ nanoparticles involves release of $\mathrm{Zn}^{+2}$ ions, which are known to inhibit active transport through the membrane, resulting in the disruption of amino acid metabolism and enzyme system [12], leading to bacterial cell death. The $\mathrm{ZnO}$ nanoparticles are known to cause changes in bacterial cell membrane potential and membrane depolarization, leading to imbalance in transport and impaired respiration, which causes bacterial cell destruction $[17,18]$. The positive charge present on the $\mathrm{ZnO}$ nanoparticles in aqueous suspension enables their interaction with bacterial cells, which have been shown to possess negative charge $[19,20]$, causing their destruction. These multiple mechanisms provide a broad spectrum of antimicrobial activity to $\mathrm{ZnO}$ nanoparticles. It has high thermal stability and is regarded as safe for being used by human beings [21]. The antimicrobial property of $\mathrm{ZnO}$ nanoparticles and the film-forming property of MWCNTs can be used to fabricate antimicrobial composite films, which may find applications in water purification [22]. Preparation of porous membranes from nanofibres coated with $\mathrm{ZnO}$ nanoparticles has been reported earlier. These membranes can be useful in applications like air filters and protective clothing [23]. Preparation of porous CNT membranes modified by chemical agents for protection against chemical and biological hazards has been reported. These membranes can be incorporated in military uniforms [24].

The CNT films and forests show highly efficient infrared (IR) radiation absorption. This property can be utilized in thermal camouflage applications by shielding warm objects using CNT films to conceal their presence from thermal IR camera.

In this paper, we have discussed the preparation of $\mathrm{ZnO}$ NR-MWCNT composite film and its potential application in antiseptic bandages, antibacterial filter for water purification and thermal IR camouflage.

\section{Experimental}

\subsection{Materials}

The MWCNT samples (NC 7000) procured from Nanocyl SA were used for making composite films. They had an average diameter of $9.5 \mathrm{~nm}$ and an average length of $1.5 \mu \mathrm{m}$. The $\mathrm{ZnO}$ NRs were procured from Smart Nanoz Pvt. Ltd. Analytical reagent (AR) grade dimethylformamide (DMF), supplied by SD Fine-Chem Limited, was used in the preparation of a dispersion of $\mathrm{ZnO}$ NRs and MWCNTs. Polyvinylpyrrolidone (PVP K30), supplied by BASF, was used as a dispersant in the preparation of $\mathrm{ZnO} \mathrm{NR}$ and MWCNT dispersion in 


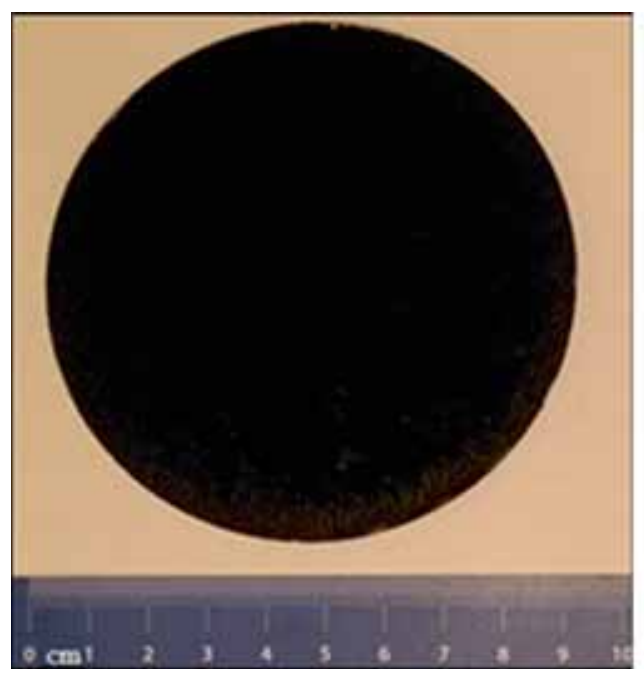

Figure 1. ZnO NR-MWCNT composite film.

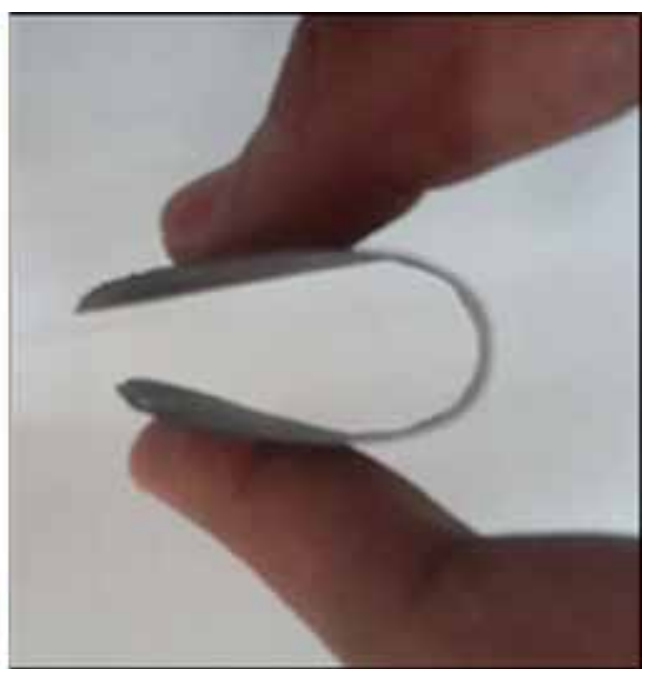

DMF. Whatman Glass fibre filter paper having $90 \mathrm{~mm}$ diameter and $1.2 \mu \mathrm{m}$ pore size was used for filtration. AR grade methanol supplied by SD Fine-Chem Limited was used for washing the films. E. coli (ATCC 25922) bacteria were used for antibacterial and bacterial filtration tests. Trychophyton mentagrophytes (T. mentagrophytes, ATCC 9533) fungus was used for antifungal test.

\subsection{Methods}

2.2a Composite film preparation: The PVP K30 (1 g) was dissolved in $100 \mathrm{~cm}^{3}$ AR grade DMF. The MWCNTs $(50 \mathrm{mg}$ ) and $\mathrm{ZnO}$ NRs $(50 \mathrm{mg}$ ) were dispersed in DMF containing PVP using ultrasonic bath for $4 \mathrm{~h}$. The dispersion was filtered through Whatman glass fibre filter paper using the laboratory filtration apparatus under vacuum. The film was washed with $50 \mathrm{~cm}^{3}$ AR grade methanol to remove residual DMF and to promote drying. The film was dried at $100^{\circ} \mathrm{C}$ in an oven for $1 \mathrm{~h}$ and peeled off from the filter paper. Similarly, a MWCNT film was prepared by dispersing $50 \mathrm{mg}$ MWCNT in $100 \mathrm{~cm}^{3}$ DMF containing $1 \mathrm{~g}$ PVP K30 and filtered through a glass fibre filter paper. For bacterial filtration experiment, the films were retained on the glass fibre filter for mechanical support. An image of the ZnO NR-MWCNT composite film is shown in figure 1 .

\subsection{Film characterization}

The films were characterized by X-ray diffraction (XRD) spectroscopy, scanning electron microscopy (SEM), Raman spectroscopy, IR spectroscopy and reflectance spectroscopy. The XRD analysis of film samples was performed on Bruker D8 Discover X-ray diffractometer. A $\mathrm{Cu}$ anode $(\mathrm{Cu}-\mathrm{K} \alpha=$ $1.5418 \AA$ ) X-ray source was used for the analysis. The surface of the film samples was examined using Nova SEM. A small piece of film sample was mounted on the conductive stub using carbon tape and the imaging was carried out without sputter coating. The Raman spectra of the film samples were recorded on 'inVia' confocal Raman microscope equipped with Nd-YAG laser having $532 \mathrm{~nm}$ excitation wavelength. For IR spectroscopy, the film samples were mixed with 100 $\mathrm{mg} \mathrm{KBr}$ powder and compressed using a manual tablet press to get $\mathrm{KBr}$ pellets. The IR spectra were recorded in the 4000 $450 \mathrm{~cm}^{-1}$ range at room temperature on the Perkin Elmer Spectrum One FTIR Spectrometer using the $\mathrm{KBr}$ pellets. Reflectance of the film samples was measured using Gretag MacBeth Coloreye 7000A color spectrophotometer in the 360-750 nm range. The Brunauer-Emmett-Teller (BET) surface area of the powder and the film samples was determined by using Micromeritics 3-Flex surface characterization analyser. The surface area measurements were performed at $77^{\circ} \mathrm{K}$ temperature using nitrogen.

\subsection{Determination of antibacterial activity}

2.4a ASTM E2149-10 test method: The film samples were cut into $1 \times 1 \mathrm{~cm}^{2}$ sized pieces, and $0.5 \mathrm{~g}$ film samples were suspended in $50 \mathrm{~cm}^{3}$ bacterial culture and agitated for $1 \mathrm{~h}$. The bacterial concentrations in the treated and untreated samples were determined and compared to determine the antibacterial property of the composite film.

2.4b AATCC 147-2011 test method: The bacterial inoculum was transferred to an agar plate in the form of parallel streaks. Films of $2.5 \times 5 \mathrm{~cm}^{2}$ size were placed transversely on the streaks and the plates were incubated for $24 \mathrm{~h}$ at $37^{\circ} \mathrm{C}$. After $24 \mathrm{~h}$, the plates were observed for bacterial growth. 


\subsection{Determination of antifungal activity}

2.5a AATCC 30, III-2004 test method: Film samples of $38 \mathrm{~mm}$ diameter were placed on a fungal colony and incubated for 10 days at $\mathrm{RH}>90 \%$ at $28^{\circ} \mathrm{C}$. After 10 days, the films were observed for fungal growth.

\subsection{Bacterial filtration}

A volume of $100 \mathrm{~cm}^{3}$ water sample containing $E$. coli bacteria was filtered through $47 \mathrm{~mm}$ diameter film sample using laboratory filtration apparatus under vacuum. The film samples and the filtered water were examined for the presence of colony forming units (CFU).

\subsection{Thermography}

The films were placed in front of an object and the images were recorded in a dark room by using Flier P65 IR camera at room temperature.

\section{Results and discussion}

\section{$3.1 \quad X$-ray diffraction}

The XRD spectra of the film samples are shown in figure 2. Curve ' $a$ ' represents the XRD spectra of $\mathrm{ZnO}$ NR powder. Curves ' $b$ ' and ' $c$ ' represent the XRD spectra of MWCNT and ZnO NR-MWCNT composite films, respectively. The MWCNT film showed a characteristic peak similar to graphite at $2 \theta=26.8$ for $\mathrm{SP}^{2}$-hybridized carbon. The $\mathrm{ZnO} \mathrm{NR}-$ MWCNT composite film showed characteristic peaks of both MWCNTs and ZnO. Peaks at $2 \theta=31.8,34.4,36.3$ and 56.6 correspond to (100), (002), (101) and (110) planes of hexagonal wurtzite $\mathrm{ZnO}$ crystal, respectively [25]. Calculation of

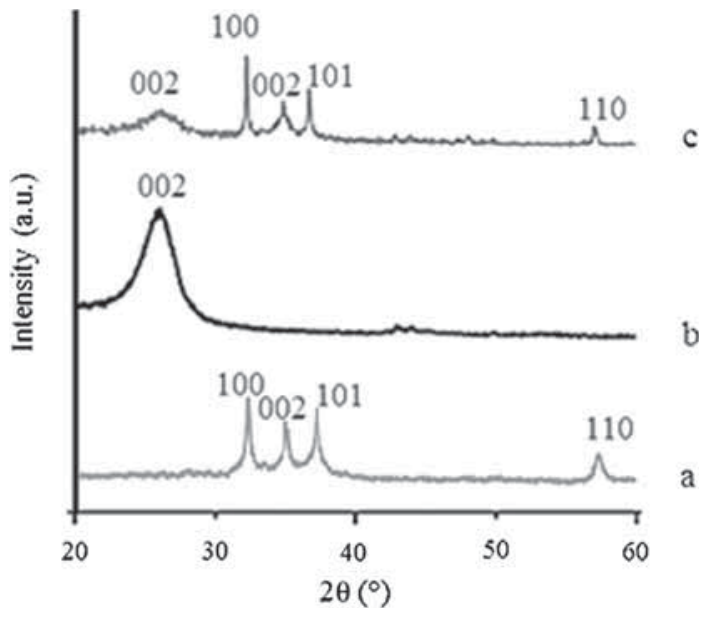

Figure 2. XRD spectra of (a) ZnO NR powder, (b) MWCNT film and (c) ZnO NR-MWCNT composite film. crystallite size using Debye Scherrer equation [26] for $\mathrm{ZnO}$ (100) peak indicated an average crystallite size of $49 \mathrm{~nm}$.

\subsection{Scanning electron microscopy}

The surface of the film samples was studied by SEM. Figure 3a shows well-dispersed and uniformly entangled MWCNTs forming the three-dimensional porous structure. The surface of the ZnO NR-MWCNT composite film is shown in figure $3 \mathrm{~b}$. The surface of $\mathrm{ZnO}$ NR-MWCNT film shows MWCNTs forming a mesh-like structure in which the $\mathrm{ZnO}$ NRs are embedded. The thin, flat and long ribbon-like structure of $\mathrm{ZnO}$ NRs seems to help in the formation of a compact and porous composite film that holds them firmly. Such porous structures may be useful in the separation of the particulate matter from air or water.

\subsection{BET surface area and pore size}

The MWCNTs and ZnO NRs showed 220.2 and $60.5 \mathrm{~m}^{2} \mathrm{~g}^{-1}$ BET surface area, respectively. The BET surface area and pore details of MWCNT and ZnO NR-MWCNT composite films are given in table 1. The MWCNT film showed $174.5 \mathrm{~m}^{2} \mathrm{~g}^{-1}$ surface area, while the ZnO NR-MWCNT composite film showed $125.9 \mathrm{~m}^{2} \mathrm{~g}^{-1}$ surface area due to the presence of $\mathrm{ZnO}$ NRs. Figure 4 shows the adsorptiondesorption isotherms obtained for the MWCNT and the $\mathrm{ZnO}$ NR-MWCNT composite films, which can be categorized as type IV isotherms exhibiting hysteresis at $P / P_{0}>0.8$. Both MWCNT and ZnO NR-MWCNT composite films showed predominant nitrogen adsorption and desorption at $P / P_{0}>$ 0.8 . Hysteresis in the isotherms can be attributed to capillary condensation in the mesopores $(2-50 \mathrm{~nm}$ diameter) present in the films, while the sharp rise in the isotherm near $P / P_{0}=1$ indicates presence of macropores (50$100 \mathrm{~nm}$ ) in the film samples [27]. Isotherms shown in figure 4 were subjected to analysis using the Barrett, Joyner and Halendar (BJH) method for estimation of the pores. The pore size distribution profiles are shown in figure 5. Average internal pore diameter of the film samples was calculated by numerical integration of the sets of curves in figure 5. While the MWCNT film showed $32.9 \mathrm{~nm}$ average pore diameter, ZnO NR-MWCNT composite film showed a slightly larger $34.3 \mathrm{~nm}$ average pore diameter. The BJH desorption curves indicate that most of the pores in film samples are mesopores. The MWCNT and the ZnO NR-MWCNT composite films showed 1.50 and $1.33 \mathrm{~cm}^{3} \mathrm{~g}^{-1}$ cumulative volume of pores between 1.7 and $300 \mathrm{~nm}$ diameter, respectively.

\subsection{Raman spectroscopy}

Raman spectroscopy is commonly used for the characterization of CNTs, which gives information about their quality and structure. The Raman spectra of the samples are shown in figure 6. Curve ' $a$ ' represents Raman spectra of $\mathrm{ZnO}$ NR powder. Curves 'b' and 'c' represent Raman spectra of MWCNT 

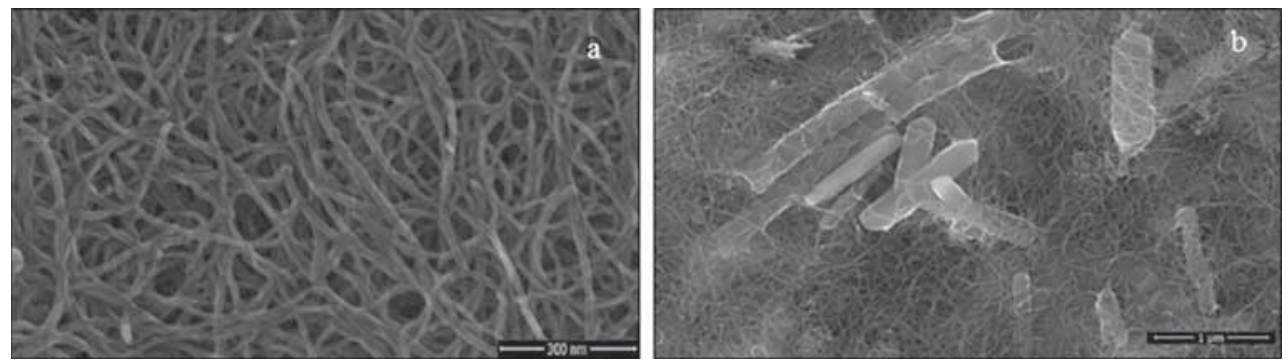

Figure 3. SEM images of (a) MWCNT film and (b) ZnO NR-MWCNT composite film.

Table 1. BET surface area and pore structure of the film samples.

\begin{tabular}{|c|c|c|}
\hline & MWCNT film & $\begin{array}{l}\text { ZnO NR-MWCNT } \\
\text { composite film }\end{array}$ \\
\hline BET surface area $\left(\mathrm{m}^{2} \mathrm{~g}^{-1}\right)$ & 174.51 & 125.96 \\
\hline BJH desorption average pore diameter (nm) & 32.99 & 34.35 \\
\hline $\begin{array}{l}\text { BJH desorption cumulative volume of pores between } 1.7 \text { and } \\
300 \mathrm{~nm} \text { diameter }\left(\mathrm{cm}^{3} \mathrm{~g}^{-1}\right)\end{array}$ & 1.50 & 1.33 \\
\hline
\end{tabular}

(a)

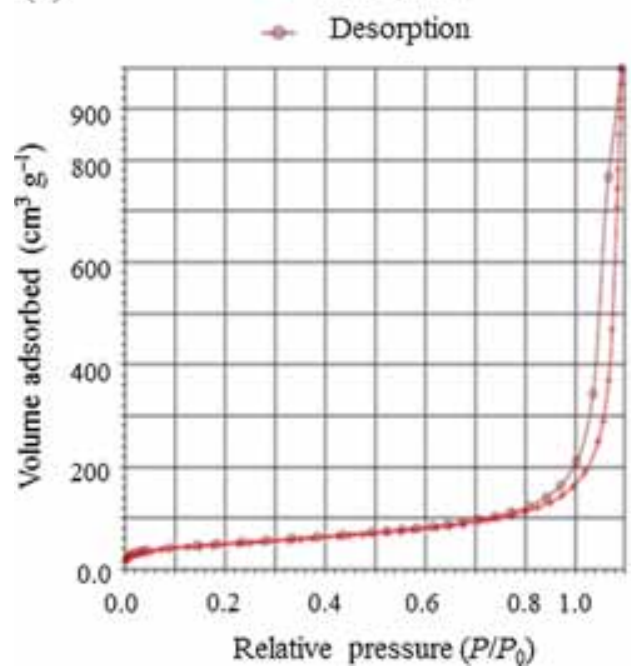

(b)

+ Adsorption

-- Desorption

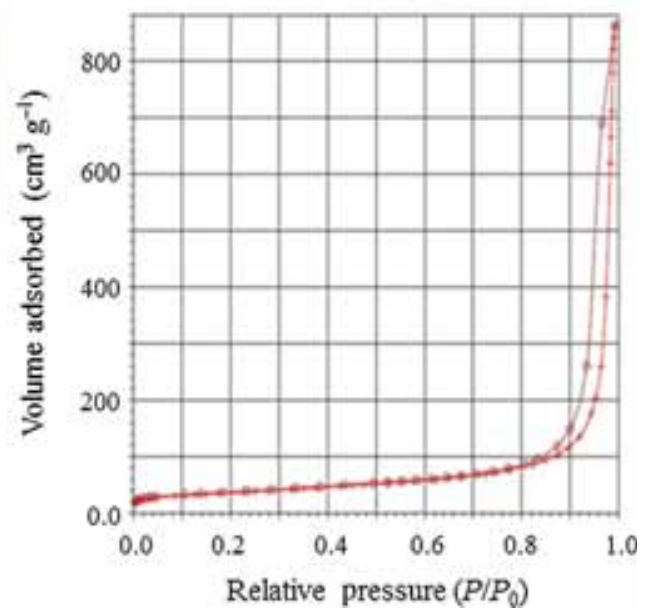

Figure 4. Nitrogen adsorption/desorption isotherms of (a) MWCNT film and (b) ZnO NR-MWCNT composite film.

and ZnO NR-WCNT composite films, respectively. The peak at $1348 \mathrm{~cm}^{-1}$ indicates D-band formed due to defects like $\mathrm{sp}^{3}$ bonding and broken $\mathrm{sp}^{2}$ bonds in the MWCNT structure [28] and the peak at $1587 \mathrm{~cm}^{-1}$ represents G-band originating from vibration of highly oriented graphitic $\mathrm{sp}^{2}$-hybridized carbon. The G-band is a characteristic of crystalline graphitic carbon in the CNTs [29]. The ratio of intensity of the D and G-bands $\left(I_{\mathrm{D}} / I_{\mathrm{G}}\right)$ indicates a measure of disorder in the CNTs [26]. The MWCNT and the ZnO NR-MWCNT composite films exhibited the $I_{\mathrm{D}} / I_{\mathrm{G}}$ ratio to be 1.23 and 1.30 , respectively. High $I_{\mathrm{D}} / I_{\mathrm{G}}$ ratio indicates a higher level of disorder in the MWCNT structure.

\subsection{IR spectroscopy}

The IR spectra of the samples are shown in figure 7. Curve 'a' represents the IR spectra of ZnO NR powder. Curves 'b' and ' $\mathrm{c}$ ' represent the IR spectra of MWCNT and ZnO NRMWCNT composite films, respectively. Peaks at 1650-1400 $\mathrm{cm}^{-1}$ range correspond to stretching modes of $\mathrm{C}=\mathrm{O}$ group and peaks at 1265 and $1020 \mathrm{~cm}^{-1}$ represent stretching vibrations of $\mathrm{C}-\mathrm{O}$ group. Peaks at 2922 and $2851 \mathrm{~cm}^{-1}$ indicate stretching vibration modes of C-H group [30-32], which can be attributed to the traces of PVP present in the film samples. Curves ' $a$ ' and 'c' show presence of characteristic peak of 

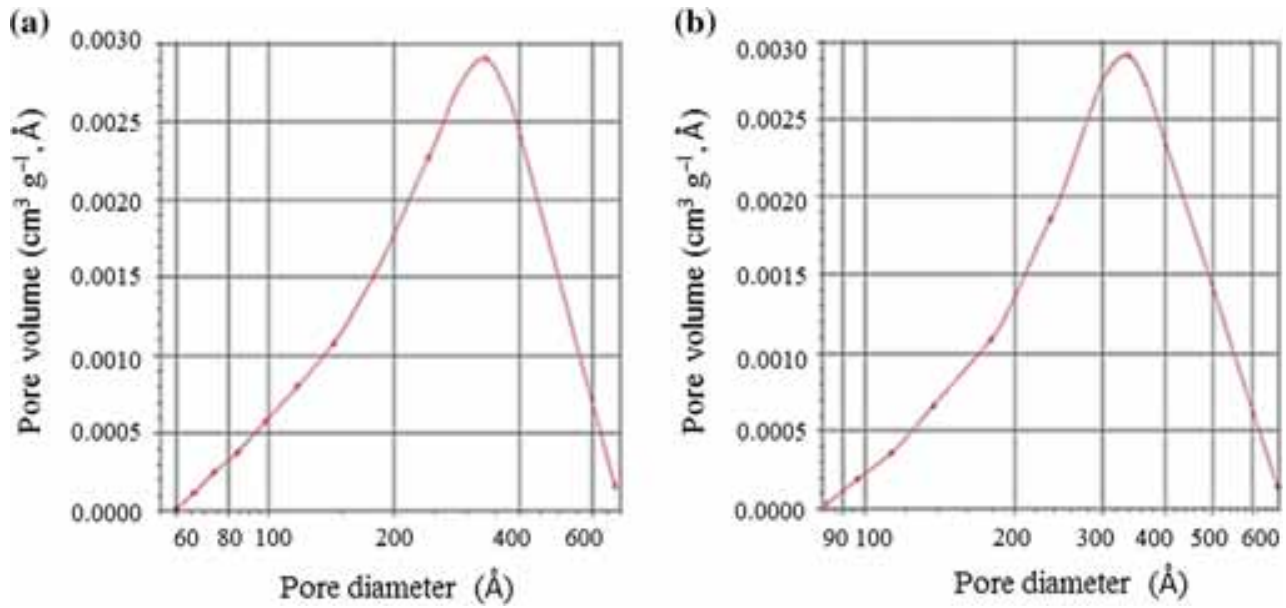

Figure 5. Pore size distribution of films by BJH method in (a) MWCNT film and (b) ZnO NRMWCNT composite film.

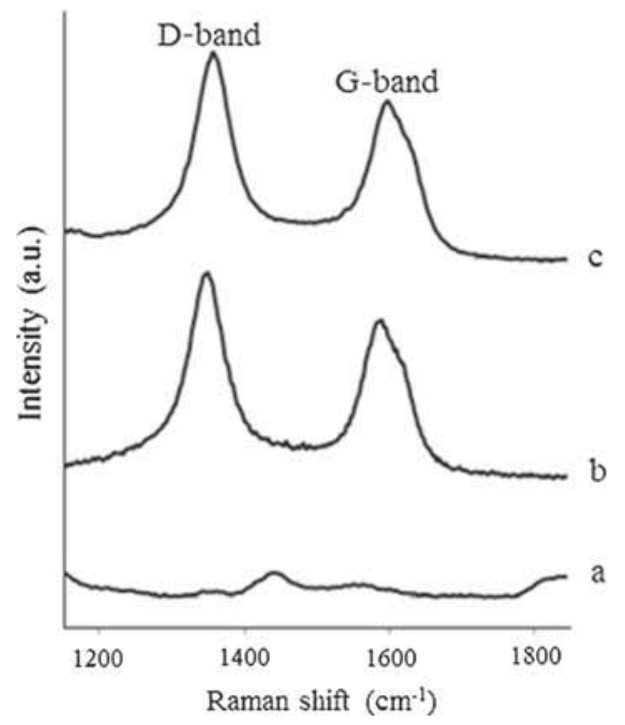

Figure 6. Raman spectra of (a) ZnO NR powder, (b) MWCNT film and (c) ZnO NR-MWCNT composite film.

$\mathrm{ZnO}$ in $550-450 \mathrm{~cm}^{-1}$ range [33]. The peaks corresponding to $\mathrm{C}=\mathrm{O}$ and $\mathrm{C}-\mathrm{O}$ groups showed increased intensity in curve ' $c$ ' compared to curve ' $b$ ', which can be attributed to the presence of $\mathrm{C}=\mathrm{O}$ and $\mathrm{C}-\mathrm{O}$ groups on the $\mathrm{ZnO}$ NR surface, which in turn might be due to use of zinc acetate as a precursor for ZnO NR synthesis.

\subsection{Reflectance spectroscopy}

Reflectance spectra of $\mathrm{ZnO}$ NR powder and films are shown in figure 8 . The $\mathrm{ZnO}$ NR powder showed high reflectance in the visible region and a sharp decrease in the reflectance below $380 \mathrm{~nm}$ due to strong absorption of ultraviolet (UV) radiation. Both MWCNT and ZnO NR-MWCNT composite films showed very low reflectance in the UV-visible region due to the radiation absorbing property of the MWCNT network. The ZnO NR-MWCNT film showed slightly higher reflectance compared to the MWCNT film due to the presence of $\mathrm{ZnO}$ NRs, which caused a slightly higher reflection in the UV-visible region.

\subsection{Application of composite film as an antimicrobial bandage material}

The $\mathrm{ZnO}$ nanoparticles are known to possess antibacterial, antifungal and antiviral properties [13,34], and they are safe for being used by humans [21,35]. The $\mathrm{ZnO}$ nanoparticles have been shown to inhibit the growth of bacteria like S. aureus, Streptococcus pyogenes and Pseudomonas aeruginosa [36] and fungi like Trichophyton rubrum, T. mentagrophytes and Microsporum canis, which are known to cause various skin infections $[37,38]$. The bacterial and fungal infections may delay the wound healing process. Application of $\mathrm{ZnO}$ nanoparticles on the wound area can provide antimicrobial action, helping the healing process [39]. Various studies have proved the suitability of CNTs as scaffolds for cell growth [6,40,41]. Tao et al [39] demonstrated application of MWCNT films for growth of mammalian fibroblasts, which play a major role in the wound healing process, by promoting collagen synthesis, which increases the strength of the wound area. Even though there are concerns about the toxicity of the CNTs, MWCNTs are known to be less cytotoxic compared to SWCNTs [42]; suitable functionalization of MWCNTs can make them biocompatible, significantly reducing their cytotoxicity [43] and making them suitable for biological applications. The ZnO NR-MWCNT composite film can be applied in the fabrication of antimicrobial bandage material used for covering wounds and minor skin injuries, providing breathable, antimicrobial and flexible bandage material that can support the growth of tissues while providing antimicrobial action and preventing skin infections. The porous structure of $\mathrm{ZnO}$ NR-MWCNT composite films may also help in faster wound healing [44]. 


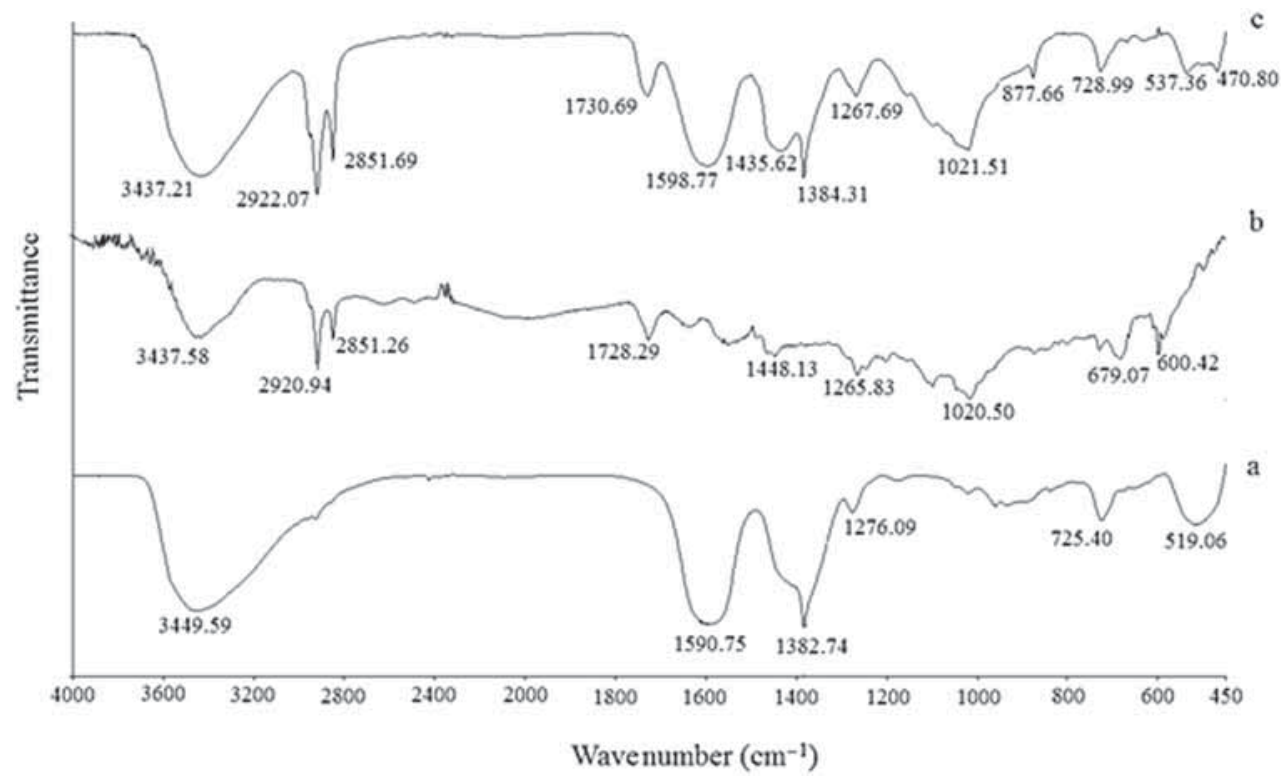

Figure 7. FTIR spectra of (a) ZnO NR powder, (b) MWCNT film and (c) ZnO NR-MWCNT composite film.

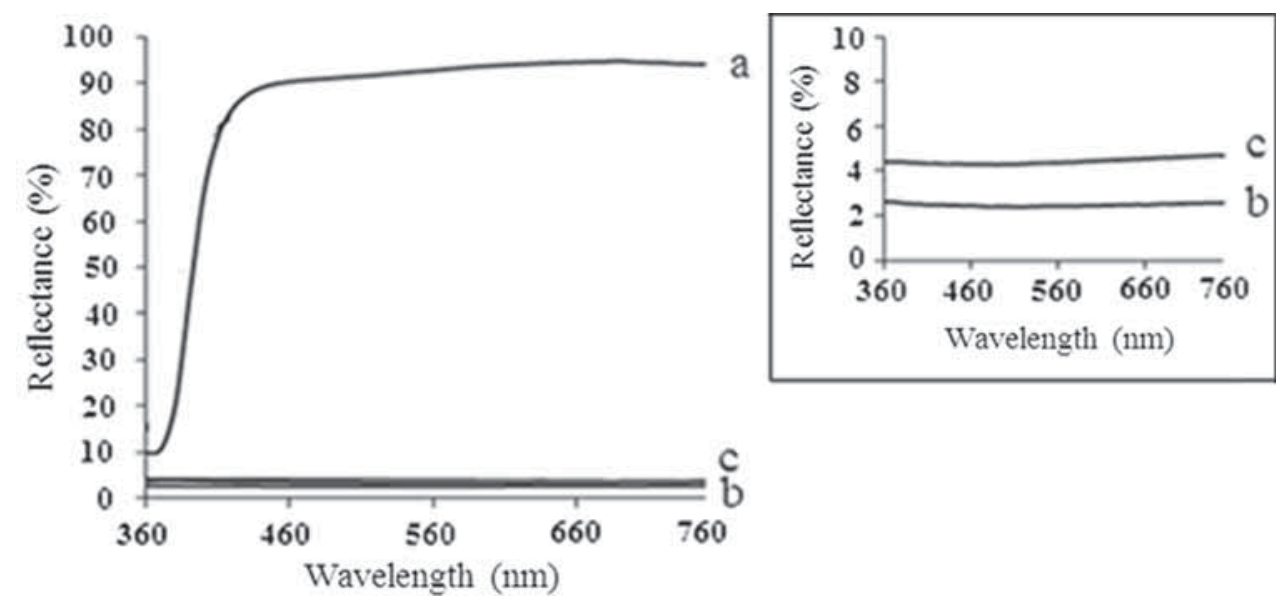

Figure 8. Reflectance spectra of (a) ZnO NR powder, (b) MWCNT film and (c) ZnO NR-MWCNT composite film.

Table 2. Results of ASTM E2149-10 antibacterial test.

\begin{tabular}{|c|c|c|c|}
\hline Film identity & $\begin{array}{l}\mathrm{CFU} \text { per } \mathrm{cm}^{3} \text { of inoculated } \\
\text { sample at } 0 \mathrm{~h}(\mathrm{~B})\end{array}$ & $\begin{array}{l}\mathrm{CFU} \text { per } \mathrm{cm}^{3} \text { of inoculated } \\
\text { sample at } 24 \mathrm{~h}(\mathrm{~A})\end{array}$ & $\begin{array}{c}\text { Reduction of } \\
\text { bacteria }(R)(\%)\end{array}$ \\
\hline MWCNT film & $1.80 \times 10^{5}$ & $1.58 \times 10^{5}$ & 12.22 \\
\hline ZnO NR-MWCNT composite film & $1.58 \times 10^{5}$ & $<10$ & $>1099.99$ \\
\hline
\end{tabular}

Reduction of bacteria $\%(R)=100(B-A) / B$.

3.7a Antibacterial property: The antibacterial property of the film samples under dynamic contact condition was determined by using the ASTM E2149-10 test method. The results of the test are summarized in table 2. The MWCNT film showed $12.22 \%$ reduction in bacterial count, which can be attributed to the direct interaction between MWCNT tip and 

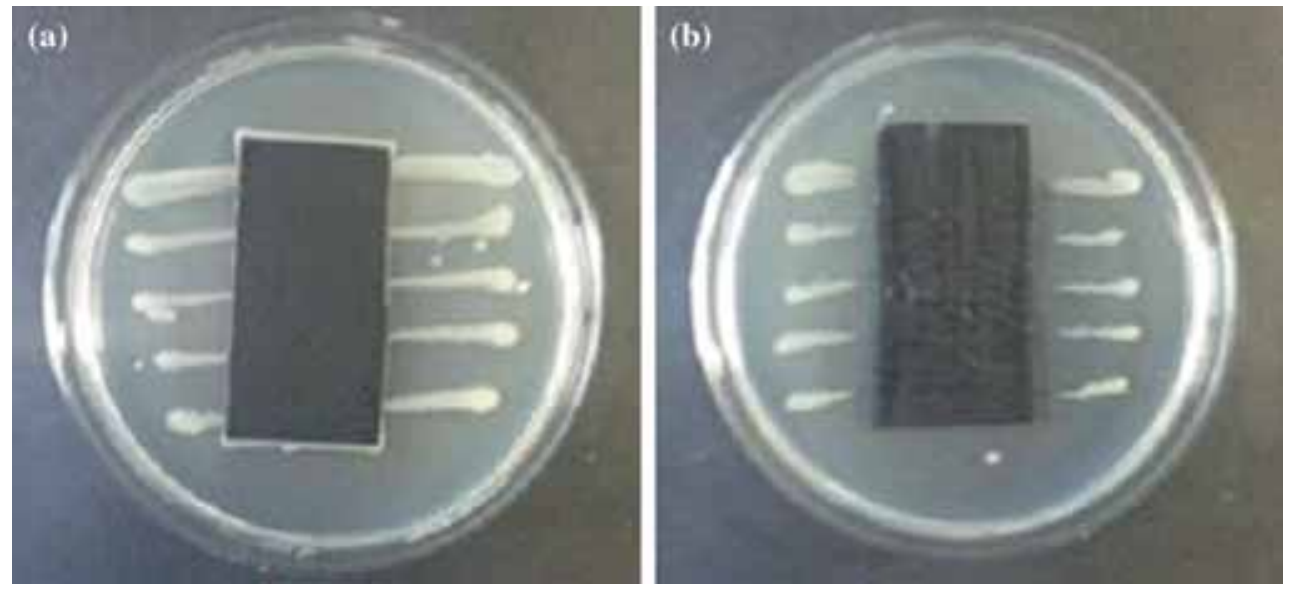

Figure 9. AATCC 147-2011 antibacterial test carried out on (a) MWCNT film and (b) ZnO NRMWCNT composite film.

the bacterial cell, as the narrow MWCNTs (average diameter $9.5 \mathrm{~nm}$ ) [45] can pierce the bacterial cell wall during shaking, leading to bacterial cell death. The ZnO NR-MWCNT composite film showed very high antibacterial activity, destroying almost all bacteria due to the strong antibacterial property of $\mathrm{ZnO} \mathrm{NRs}$ and proving that the films are very effective in killing bacterial cells on contact.

The antibacterial activity of the film samples under static condition was determined using AATCC 147-2011 method. Images of the film samples are shown in figure 9. The MWCNT film did not show antibacterial activity in static condition and bacterial growth was observed around the MWCNT film. In case of ZnO NR-MWCNT composite film, inhibition zones were clearly observed near the film and no bacterial growth was observed around the ZnO NR-MWCNT composite film due the antibacterial action of ZnO NRs. While there was no zone of inhibition in case of MWCNT film, $\mathrm{ZnO}$ NR-MWCNT film showed $5.5 \mathrm{~mm}$ inhibition zone.

3.7b Antifungal property: Antifungal property of the film samples was studied by AATCC 30, III method using T. mentagrophytes fungus. The $T$. mentagrophytes grows on skin and can cause infections like athletes foot, nail infection, jock itch, ringworm, infection of hair, scalp etc. Application of ZnO NR-MWCNT composite film for covering wounds and skin injuries can provide effective protection from fungal infections. To study the antifungal property, film samples of $38 \mathrm{~mm}$ diameter were placed on the fungal colony and incubated at $28^{\circ} \mathrm{C}$ for 10 days at RH $>90 \%$. After 10 days, the film surface was observed for fungal growth. As seen in figure 10, the MWCNT film showed no resistance to fungal growth and heavy growth was observed on it. The MWCNT film can be identified at the centre of the Petri dish due to its dark appearance. No fungal growth was observed on the $\mathrm{ZnO}$ NR-MWCNT composite film, proving its antifungal property. The ZnO NR-MWCNT composite film showed $1.5 \mathrm{~mm}$ inhibition zone.
The porous nature of the ZnO NR-MWCNT composite film can provide a barrier between the wound or the injured skin and the external environment, thus preventing infection; aiding in absorbing exudates like plasma, blood and other fluids; and accelerating the wound healing process [46]. Our study shows that the ZnO NR-MWCNT composite film can provide effective skin protection from both bacterial and fungal infections. Detailed clinical studies are required to be carried out to determine the safety aspects and the efficacy of the composite film as an antimicrobial bandage material.

\subsection{Application as an antibacterial filter}

Depending on the materials used in the fabrication, water filters can perform various functions like filtration, deodorization, disinfection and removal of organic impurities by adsorption. Water purifier fabricated by using $\mathrm{ZnO}$ nanorods, grown on polyethylene fibres and enclosed in a glass tube has been shown to destroy bacteria during the filtration process. The bacterial cells were immobilized on $\mathrm{ZnO}$ nanorods during passage through the purifier, and the interaction of bacterial cells with superoxide and hydroxyl radicals under room lighting conditions resulted in inactivation of $80 \%$ of E. coli and $59 \%$ of S. aureus bacterial cells [47]. Brady-Esétvez et al [7] prepared SWCNT membranes by depositing SWCNTs on a PVDF membrane and showed that the membrane was capable of removing bacteria and virus from water. High filtration efficiency of the CNT membranes can be combined with high antibacterial activity of $\mathrm{ZnO}$ nanoparticles by making $\mathrm{ZnO}$ MWCNT composite membranes. The $\mathrm{ZnO}$ nanoparticles present in the membrane can impart strong broad-spectrum antimicrobial property to the composite membrane and can prevent formation of biofilms on the filtration membrane, increasing the life of the filter. Such ZnO NR-MWCNT membranes can be used in filtration applications, where the 

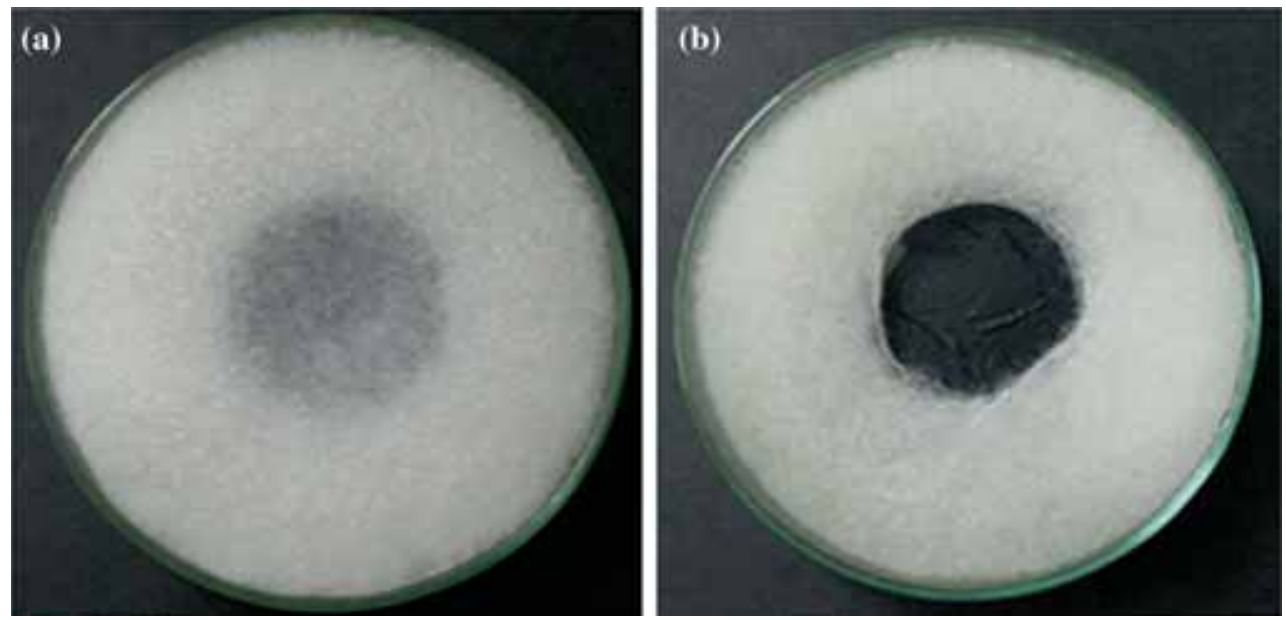

Figure 10. AATCC 30, III antifungal test carried out on (a) MWCNT film and (b) ZnO NR-MWCNT composite film.

MWCNT network can remove bacteria from air or water due to their small pore size and the $\mathrm{ZnO}$ nanoparticles can destroy the bacteria retained on the film surface.

The ability of the ZnO NR-MWCNT composite film to remove $E$. coli bacteria from water was evaluated by filtration of aqueous suspension of the bacteria through the film. Water sample containing E. coli bacteria was prepared by using buffered distilled water having a $\mathrm{pH}$ of 7.4. The buffered water was spiked with a laboratory strain $E$. coli and the concentration of the bacteria in the spiked water was determined by filtering $100 \mathrm{~cm}^{3}$ of the spiked water through a nylon membrane filter having $0.45 \mu \mathrm{m}$ pore size. The number of bacteria retained on the filter was estimated by the culture method. The nylon membrane filter was laid on Lysogeny broth (LB) agar nutrient medium and incubated at $37^{\circ} \mathrm{C}$ for $24 \mathrm{~h}$. After $24 \mathrm{~h}$, the incubated filter membrane was stained by eosin methylene blue (EMB) dye solution and the colonies were counted to check the number of CFUs present in $100 \mathrm{~cm}^{3}$ of water sample. The image of the nylon filter membrane is shown in figure 11. The concentration of bacteria in the spiked water was found to be approximately $50 \mathrm{CFUs}$ per $100 \mathrm{~cm}^{3}$.

For water filtration experiment, $100 \mathrm{~cm}^{3}$ bacterial suspension having $50 \mathrm{CFUs}$ per $100 \mathrm{~cm}^{3}$ concentration was filtered through MWCNT and ZnO NR-MWCNT composite films. The films were laid on the LB nutrient medium and incubated at $37^{\circ} \mathrm{C}$ for $24 \mathrm{~h}$ and stained by EMB dye solution. Visual observation of MWCNT film showed the presence of bacterial colonies on the film surface (figure 12a). Microscopic examination of MWCNT film showed presence of 38 bacterial colonies, indicating presence of 38 CFUs retained on the film. The surface of the $\mathrm{ZnO}$ NRMWCNT film (figure 12b) showed complete absence of bacterial colonies, as all the bacteria retained on the film surface were destroyed by the antibacterial action of $\mathrm{ZnO}$ NRs.

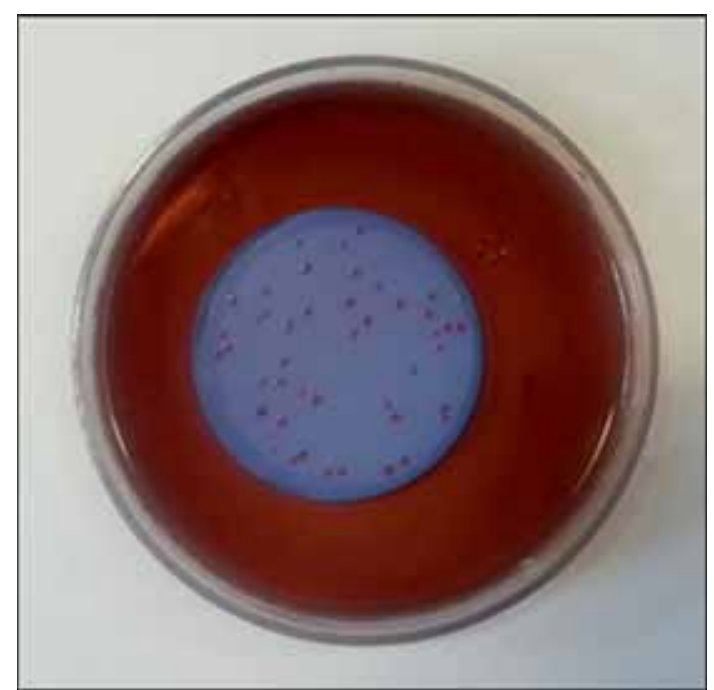

Figure 11. Nylon filter showing bacterial colonies.

The filtrate samples were analysed for the presence of bacteria by filtering through the nylon membrane filter and incubating the nylon filters on nutrient medium for $24 \mathrm{~h}$ at $37^{\circ} \mathrm{C}$. Both nylon membrane filters showed complete absence of bacterial colonies, indicating complete removal of bacteria in the spiked water sample by MWCNT and ZnO NRMWCNT composite films, thus effectively separating the bacteria from water. Presence of 38 colonies on the surface of MWCNT film compared to 50 CFUs present in $100 \mathrm{~cm}^{3}$ spiked water indicated destruction of a few bacterial cells due to interaction with MWCNT during filtration. In case of ZnO NR-MWCNT composite film, ZnO NRs provided strong antibacterial property to the composite film, killing all the bacteria retained on the film surface. 

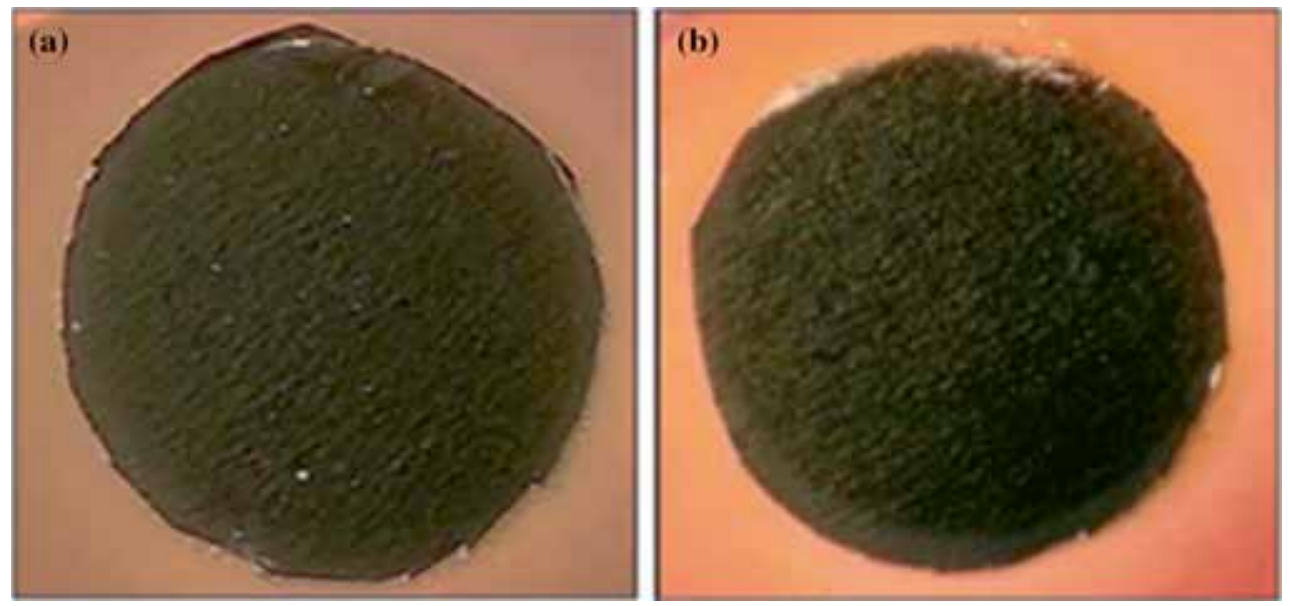

Figure 12. Film samples stained with EMB dye after bacterial filtration test. (a) MWCNT film and (b) ZnO NR-MWCNT composite film.

\subsection{Camouflage application}

The camouflage application involves concealing the presence of an object by making it appear to be a part of the surrounding. Camouflage can be of various types, like visual camouflage, shape camouflage and thermal (IR) camouflage. All objects above absolute zero temperature emit IR radiation, and the amount of IR radiation emitted by an object increases with its temperature. Spectral radiance of an object is given by the equation

$$
M(\lambda, T)=S(\lambda, T) \varepsilon(\lambda, T)=\frac{2 \pi h c^{2}}{\lambda^{5}} \frac{1}{e^{h c / \lambda K_{\mathrm{B}}^{T}-1}} \varepsilon(\lambda, T),
$$

where $\lambda$ is the wavelength of the radiation and $T$ is the absolute temperature. $M(\lambda, T)$ and $S(\lambda, T)$ indicate spectral radiance of the object and a black body, respectively; $\varepsilon(\lambda, T)$ is the spectral emissivity of the surface; $h$ is Planck's constant; $c$ is the speed of light in vacuum; and $K_{\mathrm{B}}$ is the Boltzmann constant [48].

Warm objects, including humans and electronic equipment, can be identified against cooler surroundings due to their higher temperature by using an IR camera, even in absence of visible illumination. The IR camera uses radiations of 9-14 $\mu \mathrm{m}$ wavelength emitted by the object to detect its presence, and the amount of IR radiation emitted by an object is used to estimate its temperature. The electric signal $U$ detected by an IR camera is given by the equation

$$
U=C\left[\varepsilon S_{\mathrm{obj}}+(1-\varepsilon) S_{\mathrm{amb}}-S_{\mathrm{cmr}}\right]=\mathrm{CM}_{\mathrm{total}},
$$

where $C$ is the constant of the IR detector and $\varepsilon$ is the integrated emissivity of the object. $S_{\mathrm{obj}}, S_{\mathrm{amb}}$ and $S_{\mathrm{cmr}}$ represent integrated thermal radiance of black body in the spectral range of the IR detector at the temperature of an object, environment and IR camera, respectively. When the total thermal radiance ' $M_{\text {total }}$ ' of the object is same as the surrounding, the IR camera cannot detect the difference between the object and the surrounding; thus, the presence of the object is concealed [48]. In thermal camouflage applications, warm bodies can be shielded by using IR radiation-absorbing films to conceal their presence from the IR camera.

The CNTs show strong absorption and very low reflectance over a wide range of UV-visible-IR spectra. The low reflectance at the CNT surface is proposed to be due to its refractive index being close to that of air, which minimizes the reflection at the CNT surface as the momentum of the incident photon is not changed [49]. Due to their vertical alignment and rough surface, the CNT forests have been shown to reflect a very small fraction of incident radiation [50]. Mizuno et al [51] demonstrated that the SWCNT forests show very low reflectance in the UV-visible-IR region of the spectrum. Gokhale et al [52] demonstrated the preparation of a thin film of MWCNTs dispersed by using nanodiamonds in poly-(methyl methacrylate), which showed 95\% absorbance of the incident IR radiation as the low-density MWCNT network showed radiation trapping property like an ideal black body, thus resulting in low reflection off the MWCNT surface and high absorption across the film thickness. The IR radiation-absorbing property of CNT film makes it useful for IR camouflage applications, where warm objects can be covered by a CNT film to avoid detection by the IR camera. Figure 13a shows the thermal image of a mobile phone. The object can be clearly identified in the thermogram against a cooler surrounding. As shown in figure $13 \mathrm{~b}$ and $\mathrm{c}$, when the object was covered by MWCNT and ZnO NR-MWCNT composite films, it appeared cooler as the IR radiation emitted by the object was absorbed by the film, reducing the contrast between the object and the surrounding in the thermogram and thus effectively concealing the presence of the object. While recording the thermograms, a small part of the object was exposed to observe the difference in the detected 
(a)

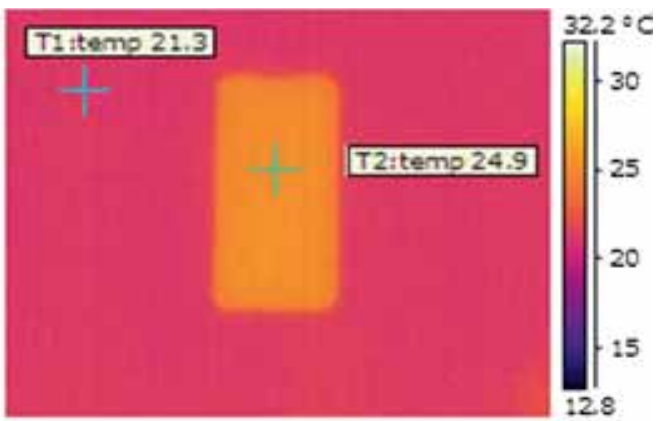

(b)

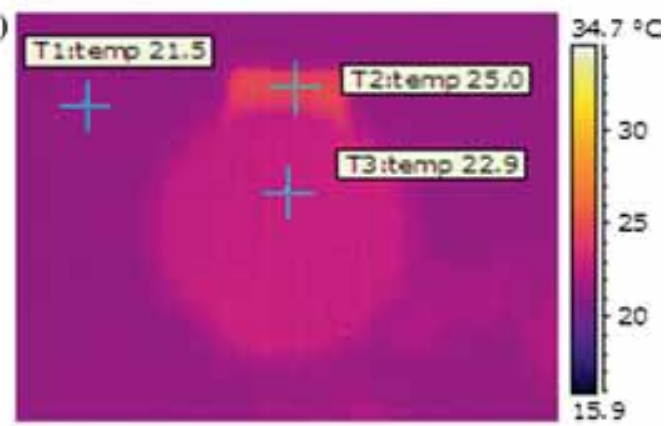

(c)

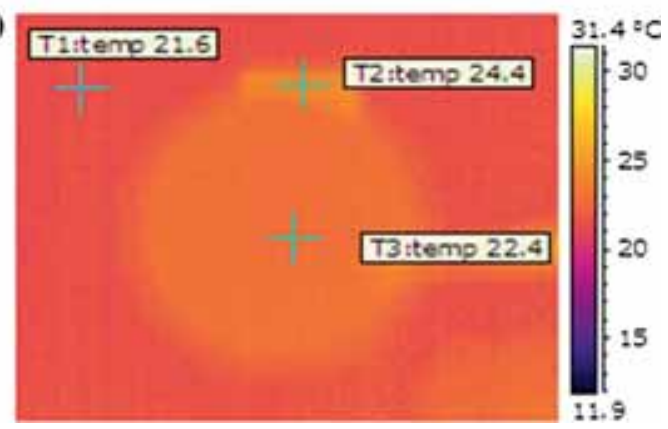

Figure 13. Thermograms of (a) the object, (b) the object covered by MWCNT film and (c) the object covered by $\mathrm{ZnO}$ NRMWCNT composite film. T1, surrounding temperature; T2, object temperature; and $\mathrm{T} 3$, object temperature detected through film sample.

temperature of the exposed part of the object and the object covered by the film. As seen in figure 13a, the object could be easily identified due to temperature difference of $3.6^{\circ} \mathrm{C}$ between the surrounding and the object. When the object was covered by MWCNT film (figure 13b), the object showed $22.9^{\circ} \mathrm{C}$ temperature, while the surrounding temperature was $21.5^{\circ} \mathrm{C}$, which reduced the temperature difference between the surrounding and the object to $1.4^{\circ} \mathrm{C}$ and the object could not be identified in the thermogram. When the object was covered by ZnO NR-MWCNT film (figure 13c), the object showed $22.4^{\circ} \mathrm{C}$ temperature, while the surrounding temperature was $21.6^{\circ} \mathrm{C}$, which further reduced the contrast between the surrounding and the object to $0.8^{\circ} \mathrm{C}$ due to the enhanced IR radiation absorption by the composite film and the presence of the object was concealed, as seen in the thermogram. This enhanced absorption of IR radiation by ZnO NR-MWCNT composite film compared to MWCNT film may be due to the presence of $\mathrm{ZnO}$ NRs in the composite film, as $\mathrm{ZnO}$ nanoparticles have been shown to absorb IR radiation [53]. Such composite films may be useful in thermal IR camouflage applications. The ZnO NR-MWCNT composite films can be used in fabricating protective clothing, which can provide protection from biological hazards and detection by thermal IR camera.

\section{Conclusion}

The ZnO NR-MWCNT composite film was prepared by simple filtration method. The porous, flexible and free-standing ZnO NR-MWCNT composite film showed a strong antimicrobial property and was also found to be useful in the absorption of IR radiation. It can be used in potential applications like antimicrobial bandage material, antibacterial filter for water purification and fabrication of protective clothing for protection from biological warfare agents and thermal IR camouflage.

\section{Acknowledgements}

We would like to acknowledge financial support from the Department of Science and Technology, Government of India (Grant No. JS\&FA/2163); University Grant Commission, Government of India (Grant No. 2202.03.102.10.01.31); and Reliance Industries Limited. We also wish to thank Pradnyesh Joshi of Reliance Industries Limited for thermography experiments.

\section{References}

[1] Walters D A, Casavant M J, Qin X C, Huffman C B, Boul P J, Ericson L M et al 2001 Chem. Phys. Lett. 33814

[2] Simmons T J, Lee S H, Park T J, Hashim D P, Ajayan P M and Linhardt R J 2009 Carbon 471561

[3] Wu Q, Zhu W, Zhang C, Liang Z and Wang B 2010 Carbon 48 1799

[4] Liu J H and Saravanan L 2014 Mater. Lett. 13430

[5] Díez-Pascual A M and Gascón D 2013 ACS Appl. Mater. Interfaces $\mathbf{5} 12107$

[6] Leng T and Fishman H A 2013 Ophthalmic Surg. Lasers Imaging Retina $\mathbf{4 4} 73$

[7] Brady-Esétvez A S, Kang S and Elimelech M A 2008 Small 4 481

[8] Rahaman M S, Vecitis C D and Elimelech M 2012 Environ. Sci. Technol. 461556

[9] Sweetman L J, Alcock L J, McArthur J D, Stewart E M, Triani G, Panhuis M et al 2013 J. Nanomater. 20131

[10] Kang S, Herzberg M, Rodrigues D F and Elimelech M 2008 Langmuir 246409

[11] Chen H, Wang B, Gao D, Guan M, Zheng L, Ouyang H et al 2013 Small 92735

[12] Sirelkhatim A, Mahmud S, Seeni A, Haida N, Kaus M, Ann L C et al 2015 Nano Micro Lett. 7219

[13] Pasquet J, Chevalier Y, Couval E, Bouvier D, Noizet G, Morlière C et al 2014 Int. J. Pharm. 46092 
[14] Banoee M, Seif S, Nazari Z E, Jafari-Fesharaki P, Shahverdi H R, Moballegh A et al 2010 J. Biomed. Mater. Res. B Appl. Biomater. 93557

[15] Brayner R, Iliou F, Brivois N, Djediat S, Benedetti M F and Fievet F 2006 Nano Lett. 6866

[16] Arabi F, Imandar M, Negahdary M, Noughabi M T, Dastjerdi H A and Fazilati M 2012 Ann. Biol. Res. 33679

[17] Liu Y, He L, Mustapha A, Li H, Hu Z Q and Lin M 2009 J. Appl. Microbiol. 1071193

[18] Pelgrift R Y and Friedman A J 2013 Adv. Drug Deliv. Rev. 65 1803

[19] Zhang L, Ding Y, Povey M and York D 2008 Prog. Nat. Sci. 18939

[20] Stoimenov P K, Klinger R L, Marchin G L and Klabunde K J 2002 Langmuir 186679

[21] Chang Y N, Zhang M, Xia L, Zhang J and Xing G 2012 Materials 52850

[22] Balamurugan R, Sundarrajan S and Ramakrishna S 2011 Membranes 1232

[23] Anne M S 2012 LLNL Newshttps://www.llnl.gov/news (Accessed on 17 Oct 2012)

[24] Segala K, Dutra R L, Franco C V, Pereira A S and Trindade T 2010 J. Braz. Chem. Soc. 211986

[25] Huang X H, Wu J B, Lin Y and Guo R Q 2012 Int. J. Electrochem. Sci. 76611

[26] Khan Z R, Khan M S, Zulfequar M and Khan M S 2011 Mater. Sci. Appl. 2340

[27] Sing K S W, Everett D H, Haul R A W, Moscou L, Pierotti R A, Rouquerol J et al 1985 Pure Appl. Chem. 57603

[28] Dresselhaus M S, Jorio A and Saito R 2010 Annu. Rev. Condens. Matter Phys. 189

[29] Sveningsson M, Morjan R E, Nerushev O A, Sato Y, Backstrom J, Campbell E E B et al 2001 Appl. Phys. A 73409

[30] http://www.umsl.edu/ orglab/documents/IR/IR.html (Accessed on 01 April 2016)

[31] http://www.chem.ucla.edu/ webspectra/irtable.html (Accessed on 01 April 2016)

[32] http://www.ochemonline.com/Infrared_spectroscopy_ absorption_table (Accessed on 01 April 2016)
[33] Lakshmipriya V, Natarajan B, Jeyakumaran N and Prithivikumaran N 2014 Int. J. Nano Dimens. 5479

[34] Mishra Y K, Adelung R, Roeh C, Shukla D, Spors F and Tiwari V 2011 Antivir. Res. 92305

[35] Colon G, Ward B C and Webster T J 2006 J. Biomed. Mater. Res. 78595

[36] Ann L C, Mahmud S, Bakhori S K M, Sirelkhatim A, Mohamad D, Hasan H et al 2014 Ceram. Int. 402993

[37] E-Diasty E M, Ahmed M A, Okasha N, Mansour S F, El-Dek S I, El-Khalek H M A et al 2013 Romanian J. Biophys. 23 191

[38] Kaiser H J and Kunze J 1982 Fortschr. Med. 1001265

[39] Tao Z, Wang P, Zhang F and Na J 2014 BioNanoSci. 4288

[40] MacDonald R A, Laurenzi B F, Viswanathan G, Ajayan P M and Stegemann J P 2005 J. Biomed. Mater. Res. A 74489

[41] Hu H, Ni Y, Montana V, Haddon R C and Parpura V 2004 Nano Lett. 4507

[42] Zhang D, Yi C, Zhang J, Chen Y, Yao X and Yang M 2007 Nanotechnology 18475102

[43] Vardharajula S, Ali S Z, Tiwari P M, Eroğlu E, Vig K, Dennis V A et al 2012 Int. J. Nanomed. 75361

[44] Mu X, Yu H, Zhang C, Chen X, Cheng Z, Bai R et al 2016 Carbohydr. Polym. 20618

[45] http://www.nanocyl.com (Accessed on 31 March 2016)

[46] Piraino F and Selimovi Š T 2015 Biomed. Res. Int.2015 1

[47] Baruah S, Pal S K and Dutta J 2012 Nanosci. Nanotechnol. Asia 290

[48] Xiao L, Ma H, Liu J, Zhao W, Jia Y, Zhao Q et al 2015 Nano Lett. 158365

[49] Garcia-Vidal F J, Pitarke J and Pendry J 1997 Phys. Rev. Lett. 784289

[50] Yang Z P, Ci L, Bur J A, Lin S Y and Ajayan P M 2008 Nano Lett. 8446

[51] Mizuno K, Ishii J, Kishid H, Hayamizu Y, Yasuda S, Futaba D N et al 2009 Proc. Natl. Acad. Sci. USA 1066044.

[52] Gokhale V J, Shenderova O A, McGuire G E and Rais-Zadeh M 2014 J. Microelectromech. Syst. 23191

[53] Fang V, Kenedy J, Futter J and Manning J 2013 GNS Sci. Rep. 3923 